\title{
An Analytical Calculation Method for Displacement Criterion on Tunnel Surrounding Rock Mass Stability
}

\author{
Zhiqiang Zhang $\mathbb{D}^{1}{ }^{1}$ Fangfang Chen, ${ }^{2}$ Mingming He, ${ }^{1}$ and Hui Wang ${ }^{1}$ \\ ${ }^{1}$ Institute of Geotechnical Engineering, Xi'an University of Technology, Xi'an 710048, China \\ ${ }^{2}$ School of Architecture and Civil Engineering, Xi'an University of Technology, Xi'an 710048, China \\ Correspondence should be addressed to Zhiqiang Zhang; zhangzq87@xaut.edu.cn
}

Received 13 August 2021; Revised 14 December 2021; Accepted 20 December 2021; Published 24 January 2022

Academic Editor: Yanbin Luo

Copyright (C) 2022 Zhiqiang Zhang et al. This is an open access article distributed under the Creative Commons Attribution License, which permits unrestricted use, distribution, and reproduction in any medium, provided the original work is properly cited.

\begin{abstract}
Assessment on the stability of a tunnel surrounding rock mass is an important issue during designing and construction of the tunnel. There is still no good enough analytical method to calculate the displacement criterion on the stability of the tunnel surrounding rock mass due to its multifactors dominated. In this paper, an innovative method to achieve the assessment displacement criterion, based on elastoplastic theory, is formed by considering multifactors, such as the quality of surrounding rock mass, initial stress, tunnel size, and supporting system. The calculation formula in this method is deduced by taking into consideration of combination the displacement and plastic region of surrounding rock mass and the reinforcement zone by systemic bolt, based on the equilibrium in elastic region, plastic region, and border between elastic region and plastic region. Furthermore, the influence of critical factors on the displacement criterion, such as deformation property and strength property of surrounding rock mass, tunnel size, and tunnel overburden, is discussed to make it clear that how these factors affect the stability of the tunnel surrounding rock mass. The validity of the analytical calculation method is testified by the application in the Zipingpu tunnel engineering.
\end{abstract}

\section{Introduction}

The evaluation of surrounding rock stability is always one of the most crucial issues in tunnel engineering, especially in design and construction phase. It also has been one of the challenging problems in the tunnel engineering community for a long period. A number of research studies have been performed to explore the stability of tunnel surrounding rock mass in rock and soil stratum $[1,2]$.

Amongst the different available experiential, analytical, and numerical methods, each method has its advantages to deal with this problem in the evaluation of tunnel surrounding rock stability. For the experiential method, it is used successfully in a large number of practical tunnel projects, but it needs enough data monitoring from tunnel construction site with larger scale coverage [3]. Numerical methods have been widely used for performing the stability analysis of tunnel project [4-6]. Most of the existing methods do not consider directly these several critical factors on stability, such as initial stress, tunnel size, and supporting system. In this paper, a new kind of analytical method on the stability analysis of tunnel is developed, and the new analytical method to calculate the displacement criterion is deduced based on the elastic and plastic theory, by consideration of the quality of tunnel surrounding rock mass, initial ground stress, tunnel size, and supporting system for tunnel.

Regarding the analytical method, some researchers have carried out deep research studies, and some results are achieved. Fraldi and Guarracino deduced an exact solution for the prediction of collapse in tunnels and natural cavities with a generic profile presented in the realm of the plasticity theory with the help of classical tools of the calculus of variations [7]. Suchowerska, Merifield, and Carter predict the roof collapse of an underground cavity by using the Hoek-Brown failure criterion [8]. However, the existing evaluation methods of surrounding rock stability are difficult to meet correctly the requirements from tunnel 
designing and construction due to the low precision and maneuver ability in the majority of real criterions, and it is difficult to carry out in practical tunnel engineering. In the analytical method, plastic region, tensile region, damaged region, maximum tensile stress, and displacement of tunnel surrounding rock mass are usually used as the stability index of tunnel surrounding rock mass [9-11], but some of indexes are difficult to obtain around tunnel during construction phase, such as plastic region, maximum tensile stress, and strain. The displacement of tunnel surrounding rock mass, which is easy relative to monitor on construction site by traditional monitoring method or last noncontact method, is selected as the index of tunnel surrounding rock stability [12-14].

In this paper, the displacement criterion is chosen to evaluate the stability of the tunnel surrounding rock mass in consideration of the multifactors, such as the quality of the tunnel surrounding rock mass, initial stress, tunnel size, and supporting system. The calculation formula is deduced by consideration of combination the displacement of surrounding rock mass, plastic region in tunnel surrounding rock mass, and the reinforcement region of systemic rock bolt. The influence law of rock mass deformation and strength property, tunnel size, and tunnel overburden on the displacement criterion is discussed by the parameter research method.

\section{Existing Methods and Their Scope of Application}

2.1. Empirical Method. Based on exploring lots of collapsing accidents on tunnel surrounding rock mass, local or entire failure occurs when the deformation of the tunnel surrounding rock mass reaches a crucial situation. The critical displacement of tunnel surrounding rock mass is mainly related to tunnel size and surrounding rock mass strength. A tunnel with horseshoe section or rectangular with arch crown section, shown in Figure 1, is with span $\boldsymbol{B}$ and height $\boldsymbol{H}$.

Based on the understanding of these factors leading to collapse, tunnel span, tunnel height, and uniaxial saturated compressive strength are employed in the empirical formula to calculate the displacement evaluation index [15]. The empirical formula of critical displacement at crown $\delta_{t}$ and wall side $\delta_{s}$ is shown as follows:

$$
\left.\begin{array}{l}
\delta_{t}=\frac{12.0 B}{R^{3 / 2}} \\
\delta_{s}=\frac{4.5 H^{3 / 2}}{R^{2}}
\end{array}\right\},
$$

where $\boldsymbol{B}$ is the tunnel span, $\boldsymbol{H}$ is the tunnel height, and $\boldsymbol{R}$ is the uniaxial saturated compressive strength of surrounding rock.

Actually, this empirical method does not consider two critical factors having especially important influence on the displacement of the tunnel surrounding rock mass. The first one is overburden relating the excavation load on surrounding rock mass, and the second one is the surrounding rock mass deformation modulus relating the displacement during excavation. So, the empirical method is not enough reason to consideration on dominating factors.

2.2. Method Recommended by Tunnel Regulation. According to a regulation on tunnel supporting in P. R. China, Technical Code for Engineering of Ground Anchorages and Shotcrete Support (GB50086-2015), a rough allowable relative convergence index in a large range is suggested for these tunnels in surrounding rock mass graded III, IV, and V based on a large number of tunnel projects, shown in Table 1.

The relative convergence index is a ratio of the cumulative displacement measured between two monitoring points and the distance between two monitoring points. According to the technical code, the lower bound is suitable for tunnel in brittle surrounding rock mass, and the upper bound is suitable for tunnel in soft surrounding rock mass.

There are two limitations on application of Table 1.

(1) The ratio of tunnel height to span is in the range of $0.8 \sim 1.2$

(2) The tunnel span is smaller than $20.0 \mathrm{~m}, 15.0 \mathrm{~m}$, and $10.0 \mathrm{~m}$, respectively, in surrounding rock mass classified III, IV, and V

In the method recommended by the technical code, tunnel size, surrounding rock mass quality, and overburden are taken into account to choose the allowable relative convergence, but the allowable relative convergence index is a rough range and too wide to apply.

An example can explain how Table 1 works. A tunnel has overburden of $100 \mathrm{~m}$ and span of $10.0 \mathrm{~m}$ in surrounding rock mass graded IV. Its allowable relative convergence index is $0.4 \sim 1.2$ according to Table 1, and the corresponding allowable convergence displacement of tunnel excavation limit is in the range of $40.0 \sim 120.0 \mathrm{~mm}$. To a specified point on excavation limit, the allowable displacement is in the range of $20.0 \sim 60.0 \mathrm{~mm}$. When the displacement at the crown is $50.0 \mathrm{~mm}$ by monitoring in-site, it is difficult to make a judgment on stability of tunnel surrounding rock mass because that the displacement at the crown by monitoring is in the range of $20.0 \sim 60.0 \mathrm{~mm}$.

The advantage of the method is that it is easy to obtain the allowable relative convergence index or displacement according to the grade of the tunnel surrounding rock mass and tunnel span. However, there is a big problem that the relative convergence displacement is in a large wide range, and it is difficult to carrying out for in-site tunnel engineer.

And another systemic problem is that there are some limitations to apply, such as tunnel span and overburden. If a tunnel is beyond these limitations, the stability of tunnel surrounding rock mass cannot be evaluated using the method.

\section{An Analytical Method Based on Elastoplastic Theory}

Regarding these existing methods, both the empirical method and the method recommended by tunnel regulation do not directly take these important influencing factors into 


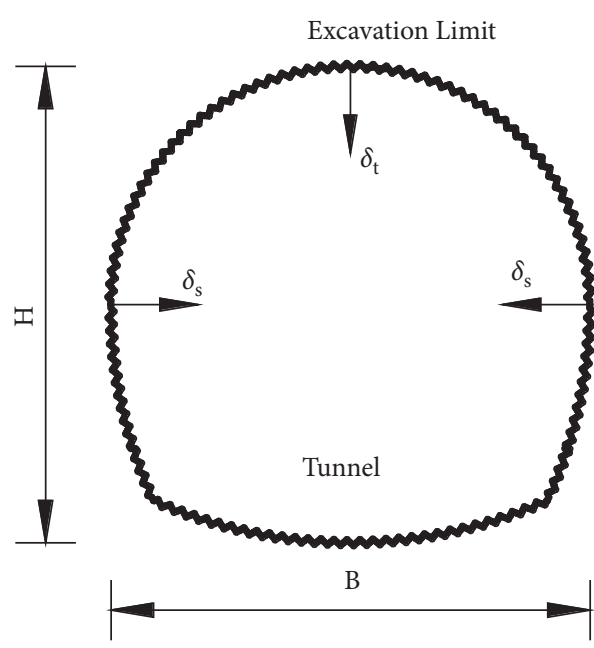

(a)

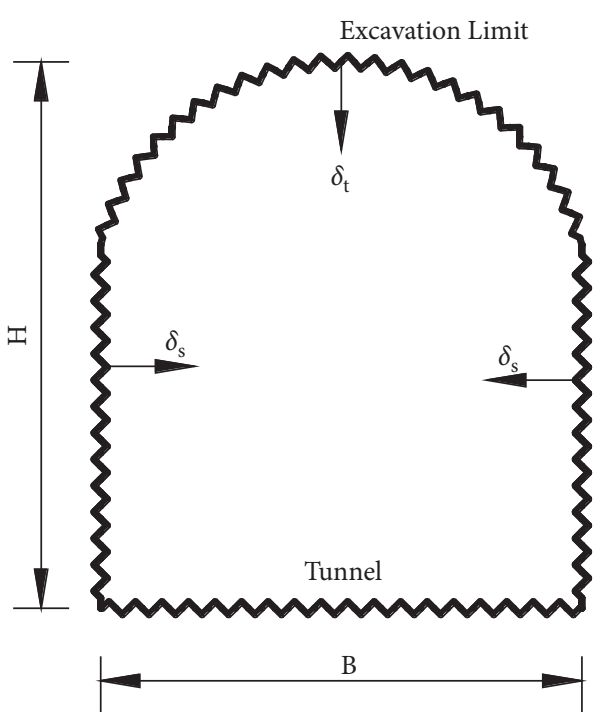

(b)

FIgURE 1: Tunnel size and excavation limit: (a) horseshoe section; (b) rectangular with arch crown section.

TABLE 1: Allowable relative convergence index for tunnel.

\begin{tabular}{lccc}
\hline Rock class & \multicolumn{2}{c}{ Tunnel overburden $(\mathrm{m})$} \\
& $<50$ & $50 \sim 300$ & $300 \sim 500$ \\
\hline $3 \backslash *$ ROMAN III & $0.10 \sim 0.30$ & $0.2 \sim 0.5$ & $0.4 \sim 1.2$ \\
$=4 \backslash *$ ROMAN IV & $0.15 \sim 0.50$ & $0.4 \sim 1.2$ & $0.8 \sim 2.0$ \\
$=5 *$ ROMAN V & $0.20 \sim 0.80$ & $0.6 \sim 1.6$ & $1.0 \sim 3.0$ \\
\hline
\end{tabular}

The relative convergence index unit is \%.

account in obtaining the allowable displacement, such as deformation and strength properties of tunnel surrounding rock mass and tunnel overburden. A new method more relative fully considered should be set up to overcome these shortcomings.

3.1. Displacement on Excavation Limit of Circular Tunnel. A circular tunnel in homogeneous rock mass, with radius $\boldsymbol{r}$ and overburden $\boldsymbol{H}_{r}$, is shown in Figure 2. If the overburden is large enough, stress, strain, and displacement around the tunnel can be solved according to the theory of elasticity $[16,17]$. If the plasticity of surrounding rock mass is taken into consideration, the plastic region in tunnel surrounding rock mass can also be achieved.

The displacement $\delta_{t}$ on the excavation limit is derived from the elastoplastic solution on the hole problem in halfspace [18], shown as follows:

$$
\delta_{t}=r\left(1-\sqrt{1-\left(2-A_{c}\right) A_{c}\left\{\left[\frac{\gamma H_{r}(1-\sin \varphi)+\operatorname{cctg} \varphi}{\left(\gamma H_{r}+\operatorname{cctg} \varphi\right)(1-\sin \varphi)}\right]^{1-\sin \phi / \sin \phi}\left(\frac{r_{p}}{r}\right)^{2}\right\}},\right.
$$

where

$$
A_{c}=\frac{1+\mu}{E} \sin \varphi\left(\gamma H_{r}+\operatorname{cctg} \varphi\right) .
$$

Here, $\boldsymbol{E}$ is the deformation modulus of surrounding rock mass; $\mu$ is Poisson's ratio of surrounding rock mass; $c$ is the cohesion of surrounding rock mass; $\varphi$ is the internal friction angle of surrounding rock mass; and $\gamma$ is the unit weight of surrounding rock mass.

Equation (2) is a universal formula to calculate the displacement on the tunnel excavation limit, and for different phases, some simplifications are made to meet the need in the construction in-site requirement. The simplification will be examined in the following part. 


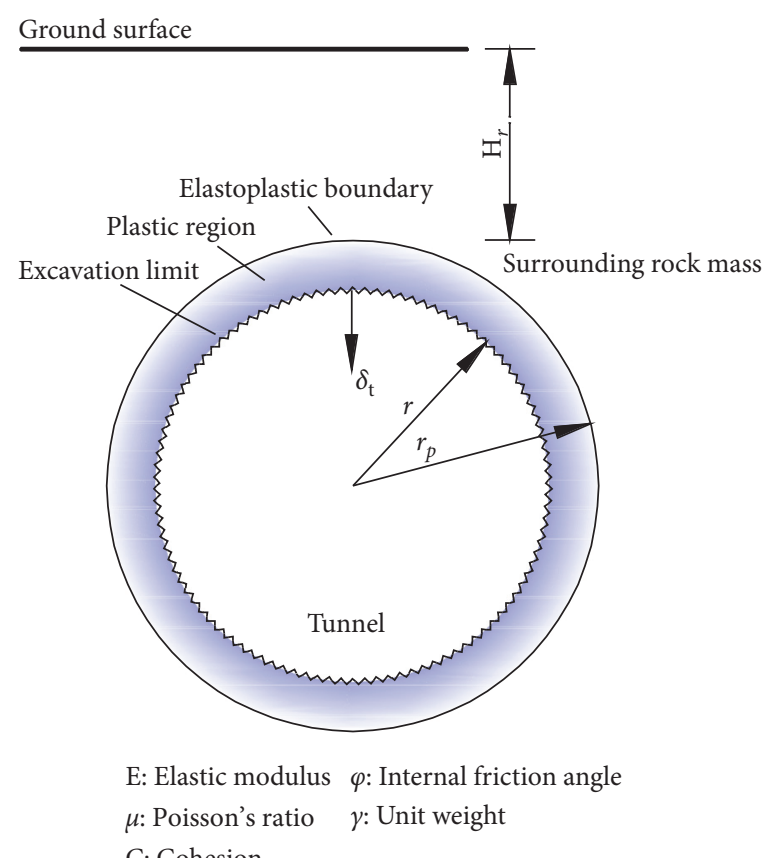

Figure 2: Circular tunnel size and surrounding rock mass.

For a strict requirement in tunnel, the plastic region is not allowed in the surrounding rock mass after excavation, that is to say, $r_{p}=r$, so equation (2) is simplified to the following equation:

$$
\delta_{t}=r\left(1-\sqrt{1-\left(2-\mathrm{A}_{c}\right) \mathrm{A}_{c}\left\{\left[\frac{\gamma H_{r}(1-\sin \phi)+c \operatorname{ctg} \phi}{\left(\gamma H_{r}+c \operatorname{ctg} \phi\right)(1-\sin \phi)}\right]^{1-\sin \phi / \sin \phi}\right\}}\right) .
$$

In the practical tunnel engineering, rock bolt is a type of common support. The length of the rock bolt can be treated as the range of reinforcement in surrounding rock mass from tunnel excavation limit to the deep end of a rock bolt, shown in Figure 3.

Under the condition that the plastic region is within the reinforcement range of rock bolt, the surrounding rock mass remains stable and the tunnel is safe. So, for a tunnel reinforced by systemic rock bolt with a length of $L_{b}$, if $\boldsymbol{r}_{p} \leq \boldsymbol{r}+\boldsymbol{L}_{b}$, the tunnel surrounding rock mass can be stable. Then, $r_{p}=\boldsymbol{r}+\boldsymbol{L}_{b}$, and equation (2) is transformed to the following equation:

$$
\delta_{t}=r\left(1-\sqrt{1-\left(2-\mathrm{A}_{c}\right) \mathrm{A}_{c}\left\{\left[\frac{\gamma H_{r}(1-\sin \phi)+c \operatorname{ctg} \phi}{\left(\gamma H_{r}+c \operatorname{ctg} \phi\right)(1-\sin \phi)}\right]^{1-\sin \phi / \sin \phi}\left(\frac{r+L_{b}}{r}\right)^{2}\right\}}\right)
$$

In equations (2)-(5), allowable displacement can be calculated with relative accuracy by consideration of the main factors. Next part, the relationship between allowable displacement and influencing factor will be discussed by using equation (4).

3.2. Discussion on Influence Law. To calculate and discuss the allowable displacements under various preconditions, a set of bias parameters are suggested in Table 2 based on the moderate rock mass.

The curve of allowable displacement vs. tunnel radius is shown in Figure 4 under the different overburden. The relationship between allowable displacement and tunnel radius is seen to be nonlinear, and there is a local valley with the tunnel radius from $2.5 \mathrm{~m}$ to $7.5 \mathrm{~m}$. Among the conditions we discuss, the lowest point of the curve is at tunnel radius 3.0 when the tunnel equals the length of rock bolt. 


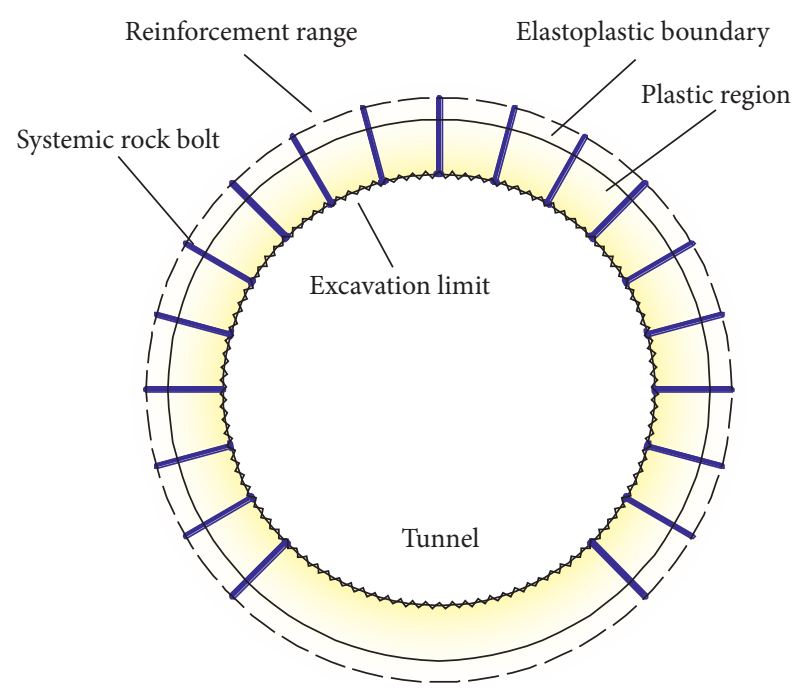

FIgURE 3: Reinforcement range and plastic region.

TABLE 2: Bias parameters to calculate allowable displacement.

\begin{tabular}{lc}
\hline Parameter & Value \\
\hline Tunnel radius $(\mathrm{m})$ & 5.0 \\
Overburden $(\mathrm{m})$ & $50,100,150$ \\
Deformation modulus $(\mathrm{GPa})$ & 5.0 \\
Poisson's ratio & 0.3 \\
Density $\left(\mathrm{kg} / \mathrm{m}^{3}\right)$ & 2500.0 \\
Cohesion $(\mathrm{MPa})$ & 0.6 \\
Internal friction angle $\left(^{\circ}\right)$ & 35.0 \\
Length of rock bolt $(\mathrm{m})$ & 3.0 \\
\hline
\end{tabular}

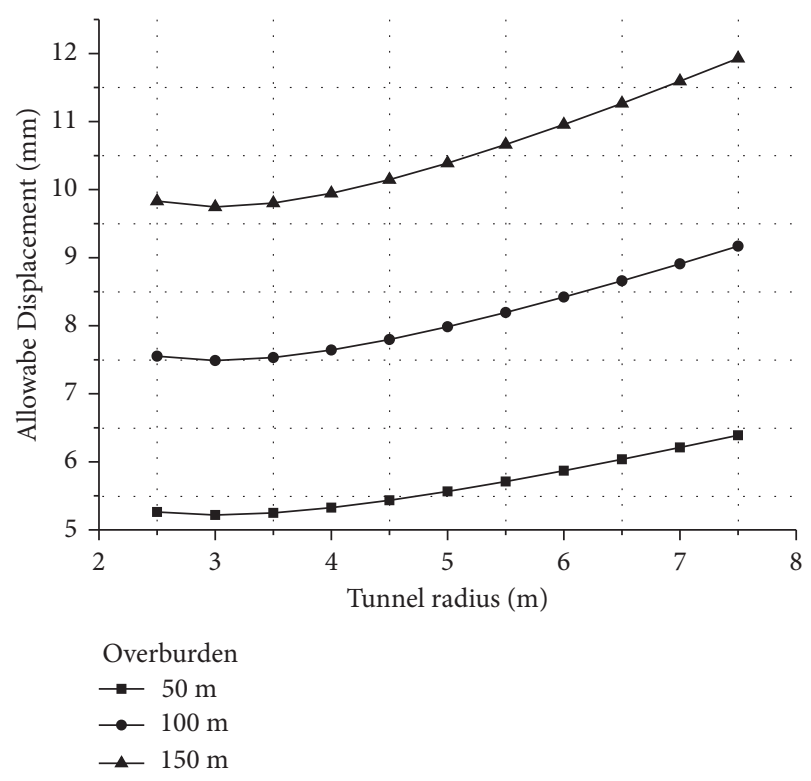

FIgURE 4: The curve of allowable displacement vs. tunnel radius.

Under the condition that the tunnel radius is less than $3.0 \mathrm{~m}$, the allowable displacements go down with the increase in the tunnel radius, but the tunnel radius is more than $3.0 \mathrm{~m}$ and the allowable displacement goes up with the increase in the tunnel radius. When the tunnel radius is $7.5 \mathrm{~m}$, the allowable displacements reach about $7.95 \mathrm{~mm}$, $10.39 \mathrm{~mm}$, and $13.15 \mathrm{~mm}$ respective to overburden $50 \mathrm{~m}$, $100 \mathrm{~m}$, and $150 \mathrm{~m}$.

For a tunnel, rock overburden, governing the initial stress in the rock stratum, is the key loading factor for the deformation of the tunnel surrounding rock mass. The curve of allowable displacement vs. tunnel overburden is presented in Figure 5, under three rock bolt lengths $2.0 \mathrm{~m}, 3.0 \mathrm{~m}$, and $4.0 \mathrm{~m}$. The relationship of allowable displacement and tunnel overburden looks like linear, and with the increase in tunnel overburden, the surrounding rock mass allowable displacement goes up. Comparing these cases with different bolt reinforcement grades, all the curves have unique itself slopes, the stronger the reinforcement is, the greater the slope is.

Depending on Figure 6, the relationship of allowable displacement and deformation modulus of tunnel surrounding rock mass is negative exponential, and with the increase in the deformation modulus, the allowable displacement goes down. In the range from 1.0 to $4.0 \mathrm{GPa}$, the allowable displacement goes down dramatically with the deformation modulus raising. Under the condition that the deformation modulus of tunnel surrounding rock mass is larger than $4.0 \mathrm{GPa}$, the allowable displacement changes smoothly with the deformation modulus increasing.

Both cohesion and internal friction angle of surrounding rock mass are these parameters concerning the strength of tunnel surrounding rock mass that has non-negligible influence on the stability of tunnel surrounding rock mass. From Figure 7, the allowable displacement rises gently with the increase in cohesion and internal friction angle of surrounding rock mass.

If the plastic region is not acceptable in surrounding rock mass, then $\boldsymbol{r}_{\mathrm{p}}=\boldsymbol{r}$; it is too strict for a common tunnel. Actually, the surrounding rock mass of the tunnel is always reinforced by rock bolt or other support system, so the rock mass is allowed to be in plastic status in the region reinforced by rock bolt. If the length of the rock bolt is $\boldsymbol{L}_{\mathrm{b}}$, then $\boldsymbol{r}_{\mathrm{p}}=\boldsymbol{r}+\boldsymbol{L}_{\mathrm{b}}$. The allowable displacement can be computed according to (4) considering the reinforced region by systemic rock bolt, and the relationship between rock bolt length and allowable displacement is illustrated in Figure 8.

According to Figure 8, the allowable displacement goes up with the increase in the length of systemic rock bolt, and the relationship between allowable displacement and length of systemic rock bolt is quadratic polynomial.

\section{Comparison between the Existing and New Methods}

Each existing method gets its advantage and disadvantage for application. For comparing these evaluation methods, a common tunnel is chosen as a typical model tunnel. The model tunnel is a circle cross section tunnel, with the diameter of $10.0 \mathrm{~m}$ and overburden of $100.0 \mathrm{~m}$. Hypothetically, the model tunnels can be located separately in rock layer with different qualities, which are classified into 3 grades, from grade III to V. According to the handbook of 


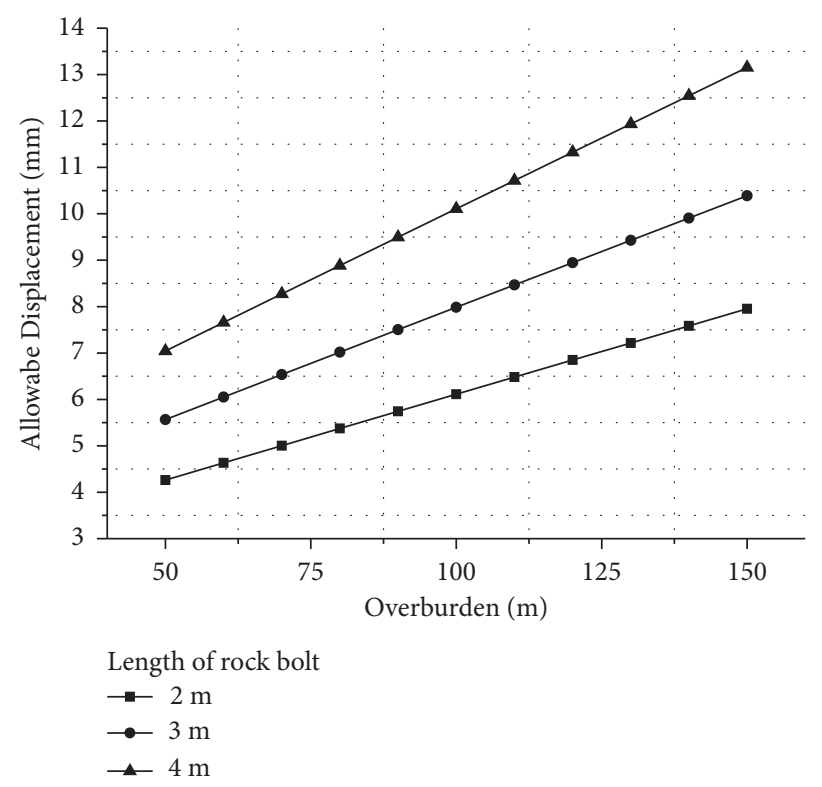

Figure 5: The curve of allowable displacement vs. tunnel overburden.

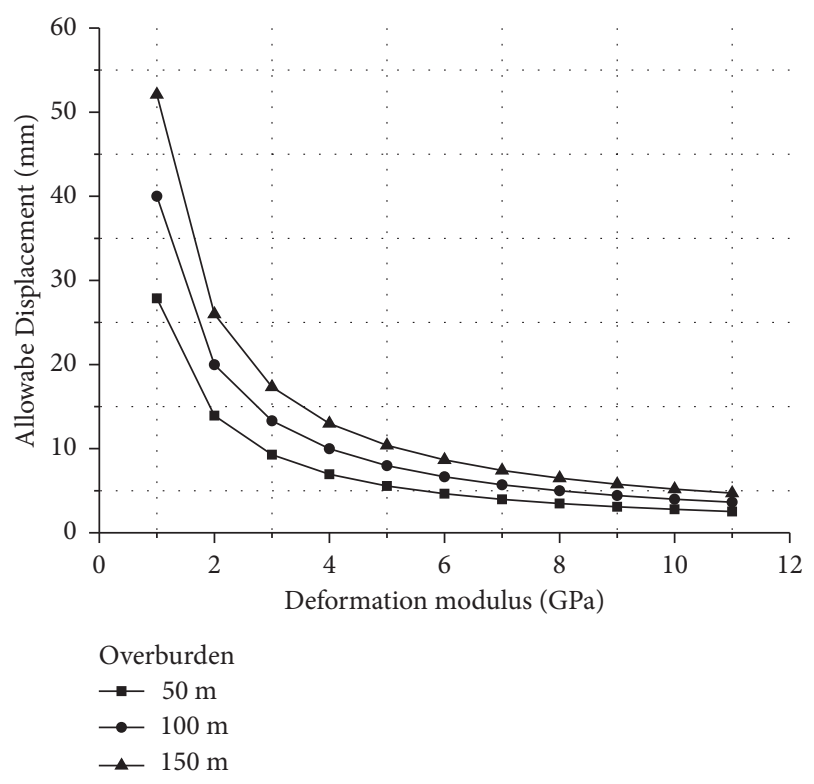

Figure 6: The curve of allowable displacement vs. deformation modulus.

underground construction in hydroelectric engineering [19], the physical and mechanical parameters of surrounding rock mass graded from III to $\mathrm{V}$ are listed in Table 3.

According to Sections 2 and 3, there are 4 methods taken into account to make a comparison: first one is the empirical method shown in (1), the second one is the method recommended by regulation indicated in Table 1, the third is the method based on the elastoplastic theory by considering no plastic region in surrounding rock mass, shown in (3), and the last is the method based on the elastoplastic theory by considering plastic region with $3.0 \mathrm{~m}$ depths in surrounding rock mass, shown in (4). The allowable displacements are listed in Table 4.
According to Table 4, if plastic region in surrounding rock mass is not taken into account, the allowable displacement is very small; generally, it is too strict to an actual tunnel. For the method suggested by regulation, allowable displacement is in a large range, and the lowest value is the one third of the biggest value, and it is difficult to make a clear judgment. So, the method with considering the plastic region is the best choice by the comparing results.

Based on the suggested method with considering plastic region in tunnel surrounding rock mass, for the tunnel located in surrounding rock mass graded III, the allowable displacement is $7.98 \mathrm{~mm}$; for the tunnel in surrounding rock mass graded IV, the allowable displacement is $23.76 \mathrm{~mm}$, and for the tunnel in surrounding rock mass graded V, the allowable displacement is $54.71 \mathrm{~mm}$.

\section{Field Investigation and Case Study}

A Zipingpu project is located in Sichuan, southwest of China. The in-site monitoring was carried out from 2001 to 2002 in the diversion tunnel during excavation.

The diversion tunnel, at milestone $0+674.0$ located in a fault $\mathrm{F} 3$, has overburden of $33.7 \mathrm{~m}$ and the equivalent radius of $8.0 \mathrm{~m}$. According to geological report, the grade of surrounding rock is $\mathrm{V}$, deformation modulus is $0.3 \mathrm{GPa}$, Poisson's ratio is 0.35 , cohesion is $5.0 \mathrm{kPa}$, internal friction angle is $20.0^{\circ}$, density is $2300.0 \mathrm{~kg} / \mathrm{m}^{3}$, and uniaxial compressive strength is $0.5 \mathrm{MPa}$. Based on a design report, the length of systemic rock bolt is $6.0 \mathrm{~m}$, so the depth of the plastic region can be set at $5.0 \mathrm{~m}$ from conservative consideration.

The allowable displacement is $94.25 \mathrm{~mm}$ by the empirical method. The allowable displacement cannot be achieved by the method in tunnel regulation because the tunnel size goes over the limitation that tunnel span is less $10.0 \mathrm{~m}$ in surrounding rock mass graded $\mathrm{V}$. The allowable displacement is 


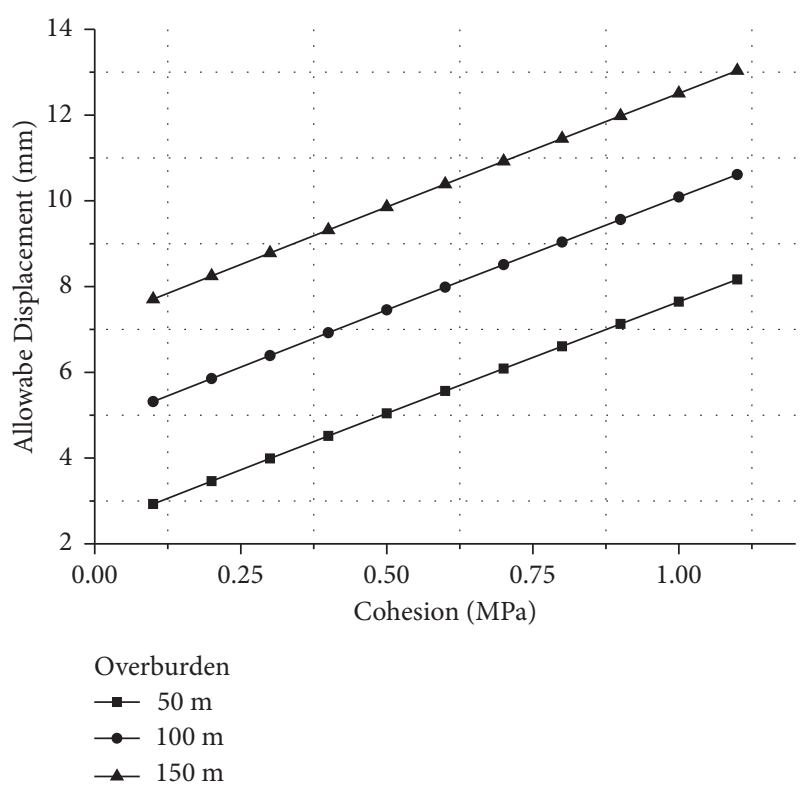

(a)

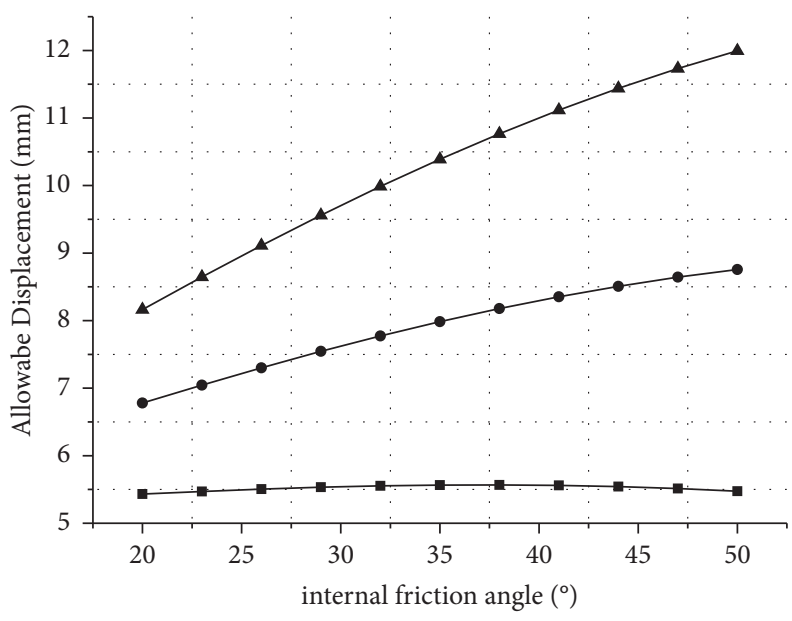

Overburden

$\rightarrow 50 \mathrm{~m}$

$\rightarrow 100 \mathrm{~m}$

- $150 \mathrm{~m}$

(b)

Figure 7: The curve of allowable displacement vs. both (a) cohesion and (b) internal friction angle.

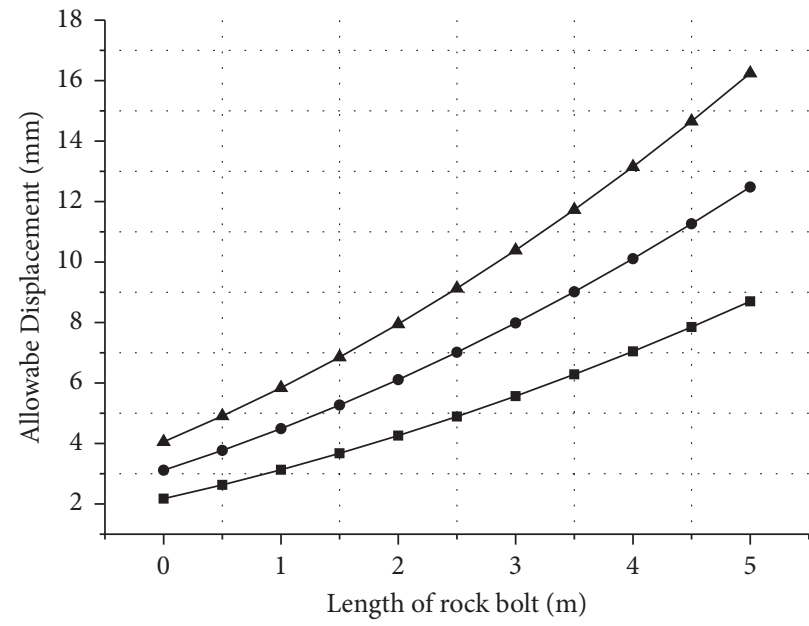

Overburden

$\rightarrow 50 \mathrm{~m}$

$\rightarrow 100 \mathrm{~m}$

- $150 \mathrm{~m}$

Figure 8: The curve of allowable displacement vs. the length of rock bolt.

TABLE 3: Physical and mechanical parameters of surrounding rock mass graded from III to V.

\begin{tabular}{lccccc}
\hline Rock grade & Deformation modulus $(\mathrm{GPa})$ & Cohesion $(\mathrm{MPa})$ & Friction angle $\left(^{\circ}\right)$ & Poisson' s ratio & Density $\left(\mathrm{g} / \mathrm{cm}^{3}\right)$ \\
\hline III & 7.5 & 1.05 & 40.0 & 0.28 & 25.0 \\
IV & 3.0 & 0.35 & 32.5 & 0.33 & 24.0 \\
V & 0.65 & 0.08 & 25.0 & 0.40 & 23.0 \\
\hline
\end{tabular}

$76.98 \mathrm{~mm}$ by the method with the plastic region. All the allowable displacements by different methods are listed in Table 5 .

At construction spot, on August 23, 2002, the total displacement by monitoring reaches $78.2 \mathrm{~mm}$. The surrounding rock mass may be stable by making an evaluation of using the empirical method. If it is judged by the method with plastic region deduced in the paper, the tunnel surrounding rock mass is not stable. The curve between displacement vs. date is presented in Figure 9, and the displacement from August 18 to August 24 increases dramatically. 
TABLE 4: Allowable displacement according to different methods.

\begin{tabular}{lcccc}
\hline \multirow{2}{*}{ Rock grade } & & \multicolumn{2}{c}{ Allowable displacement $(\mathrm{mm})$} \\
& Empirical method & Method by regulation & Method without plastic region & Method with plastic region \\
\hline III & 3.79 & $10-25$ & 2.41 & 7.98 \\
IV & 10.73 & $20-60$ & 8.36 & 23.76 \\
V & 120.00 & $30-80$ & 18.76 & 54.71 \\
\hline
\end{tabular}

TABle 5: Allowable displacement by different methods for the tunnel at Zipingpu project.

\begin{tabular}{lccc}
\hline Empirical method $(\mathrm{mm})$ & Method by regulation & No plastic region method $(\mathrm{mm})$ & Method with plastic region $(\mathrm{mm})$ \\
\hline 94.25 & Not applicable & 28.67 & 76.98 \\
\hline
\end{tabular}

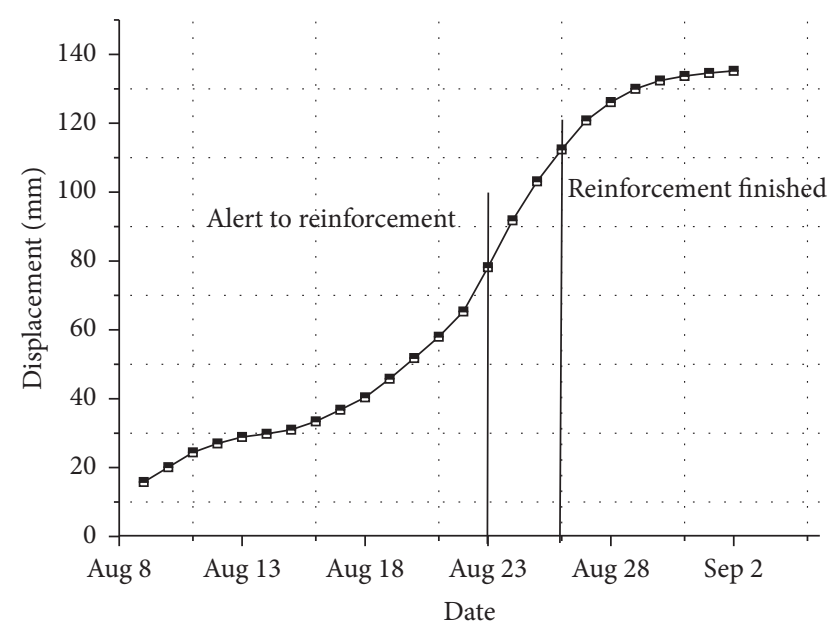

Figure 9: The curve between displacement and date at the $0+674.0$ section.

It seems that the surrounding rock mass should be reinforced or the collapsing well happens. According to evaluation by the method with the plastic region, the surrounding rock mass is unstable. An alert is launched to a requirement on reinforcement of surrounding rock mass. After a rush grouting and bolting during August 25 to August 26, the curve of displacement goes gentle. The collapsing is predicted successfully and prevented from happening by the method with plastic region in Zipingpu project.

\section{Conclusions}

Based on directly consideration of these key factors to the stability of tunnel surrounding rock mass and an elastoplastic solution on the cavern problem in semi-infinite space, a new method of calculation on allowable displacement for assessment the stability of tunnel surrounding rock mass is suggested in this paper. Some conclusions can be drawn as follows:

(1) The new method is more reasonable because that some key factors are taken directly into account on influence the stability of the tunnel surrounding rock mass, such as tunnel size, tunnel overburden, plastic region, deformation, and strength properties of tunnel surrounding rock.
(2) The influences of critical factors, such as deformation property and strength property of surrounding rock mass, tunnel size, and tunnel overburden on the displacement criterion, are discussed to make it clear that how these factors affect the stability of the tunnel surrounding rock mass. And the influence law is summarized by means of sensitivity analysis.

(3) The new method is more convenient to carry out because the displacement criterion is a specific value but a range in value. And the new method is effective for the assessment on tunnel surrounding rock mass stability.

\section{Data Availability}

The data used to support the findings of this study are included within the article.

\section{Conflicts of Interest}

The authors declare that there are no conflicts of interest.

\section{Acknowledgments}

The scientific research program was supported by the National Natural Science Foundation of China (11872301), Natural Science Basic Research Program of Shaanxi (2020JM-453), and Shaanxi Provincial Education Department Researching Foundation (17JS091).

\section{References}

[1] C. Carranza-Torres and C. Fairhurst, "The elasto-plastic response of underground excavations in rock masses that satisfy the hoek-brown failure criterion," International Journal of Rock Mechanics and Mining Sciences, vol. 36, no. 6, pp. 777-809, 1999.

[2] A. M. Ouchi, R. Pakalnis, and T. M. Brady, "Update of span design curve for weak rock masses," in Proceedings of the 99th Annual AGM-CIM Conference, Edmonton, Canada, January 2004.

[3] E. Hoek and E. T. Brown, "Empirical strength criterion for rock masses," Journal of the Geotechnical Engineering Division, vol. 106, no. 9, pp. 1013-1035, 1980.

[4] B. Ukritchon and S. Keawsawasvong, "Three-dimensional lower bound finite element limit analysis of Hoek-Brown 
material using semidefinite programming," Computers and Geotechnics, vol. 104, pp. 248-270, 2018.

[5] R. Zhang, Y. Xiao, M. Zhao, and H. Zhao, "Stability of dual circular tunnels in a rock mass subjected to surcharge loading," Computers and Geotechnics, vol. 108, no. 4, pp. 257-268, 2019.

[6] S. Liu, Y. Shi, R. Sun, and J. Yang, "Damage behavior and maintenance design of tunnel lining based on numerical evaluation," Engineering Failure Analysis, vol. 109, no. 3, Article ID 104209, 2019.

[7] M. Fraldi and F. Guarracino, "Analytical solutions for collapse mechanisms in tunnels with arbitrary cross sections," International Journal of Solids and Structures, vol. 47, no. 2, pp. 216-223, 2010.

[8] A. M. Suchowerska, R. S. Merifield, J. P. Carter, and J. Clausen, "Prediction of underground cavity roof collapse using the Hoek-Brown failure criterion," Computers and Geotechnics, vol. 44, pp. 93-103, 2012.

[9] P. Chambon and J. F. Corté, "Shallow tunnels in cohesionless soil: stability of tunnel face," Journal of Geotechnical Engineering, vol. 120, no. 7, pp. 1148-1165, 1994.

[10] W. Schubert and A. Steindorfer, "Selective displacement monitoring during tunnel excavation," Felsbau, vol. 14, no. 2, pp. 93-97, 1996.

[11] A. R. Beyabanaki and V. Gall, "3D numerical parametric study of the influence of open-pit mining sequence on existing tunnels," International Journal of Mining Science and Technology, vol. 27, no. 3, pp. 459-466, 2017.

[12] D. Kolymbas, "Tunnelling and tunnel mechanics," Tunnelling and Tunnel Mechanics, Springer, Berlin, Germany, 2005.

[13] K. Yamamoto, A. V. Lyamin, D. W. Wilson, S. W. Sloan, and A. J. Abbo, "Stability of a circular tunnel in cohesive-frictional soil subjected to surcharge loading," Computers and Geotechnics, vol. 38, no. 4, pp. 504-514, 2011.

[14] N. Liu, L. Ning, C. Xu, Z. Song, and M. Yang, "Mechanism of secondary lining cracking and its simulation for the dugongling tunnel," Rock Mechanics and Rock Engineering, vol. 53, no. $9,2020$.

[15] E. Hoek, "Practical rock engineering," Environmental and Engineering Geoscience, vol. 14, no. 1, pp. 55-57, 2007, https:// www.rocscience.com.

[16] K.-H. Park and Y.-J. Kim, "Analytical solution for a circular opening in an elastic-brittle-plastic rock," International Journal of Rock Mechanics and Mining Sciences, vol. 43, no. 4, pp. 616-622, 2006.

[17] S. K. Sharan, "Analytical solutions for stresses and displacements around a circular opening in a generalized HoekBrown rock," International Journal of Rock Mechanics and Mining Sciences, vol. 45, no. 1, pp. 78-85, 2008.

[18] H. Kastner, Statik des Tunnel-und Stollenbaues auf der Grundlagen geomechanischer Erkenntnisse, Springer-Verlag, Berlin, Germany, 2013.

[19] L. Duan, Design Handbook of Underground Construction in Hydro-Electric Engineer, Chen Du: Sichuan Scientific \& Techincal Publishers, Chengdu, China, 1993. 